\title{
Changes in Metastatic Castration Sensitive Prostate Cancer
}

\author{
(D) Mustafa Gürbüz, (1) Yüksel Ürün \\ Ankara University Faculty of Medicine, Department of Medical Oncology, Ankara, Turkey
}

\begin{abstract}
Prostate cancer is the second most common cancer in men worldwide, with approximately 1,276,106 new patients and 358,989 new deaths. Metastatic castrationsensitive prostate cancer may be de novo metastatic, but also it may be in the localized disease stage at the time of diagnosis, and may present as biochemical relapse and later metastatic disease over time. Purposes of metastatic castration-sensitive prostate cancer treatment are prolonging survival, improving quality of life and reducing complications. In this review, it is aimed to evaluate the current developments in metastatic castration-sensitive prostate cancer treatment.

Keywords: Prostate cancer, castration sensitive, treatment, chemotherapy
\end{abstract}

\section{Introduction}

\section{Overview of Prostate Cancer}

Prostate cancer $(\mathrm{PC})$ is the second most common cancer in men worldwide, with nearly 1,276,106 new patients and 358,989 new deaths worldwide (1). PC is responsible for one out of every 5 cancers in men in the United States of America (USA), and is the second most common cause of cancer-related deaths (2). In the USA, according to the Surveillance, Epidemiology and End Results (SEER) database, an estimated 174,650 new patients (9.9\% of all newly diagnosed cancers) and 31,620 deaths $(5.2 \%$ of cancer related deaths) are expected in 2019. Again, according to the SEER database, 5-year survival in PC is $98 \%$, the majority of patients are diagnosed at an early stage and the median age at diagnosis is 66 , and the median age at death is 80 . Incidence and mortality in PC decrease or stabilize in many parts of the world (3).

In our country, according to 2015 Turkey cancer statistics of the Cancer Agency Presidency, PC is the second most common cancer after lung cancer in men with frequency of $33.1 / 100,000$ according to given standardized rate of 10 cancers by age while in the second frequency; while it is the second most common cancer with $13.2 \%$ among men between the ages of 50-69 (4).

Treatment of Metastatic Castration Sensitive Prostate Cancer

Metastatic castration sensitive PC (mCSPC) may be de novo metastatic, or may be in the localized disease stage at the time of diagnosis and may present as biochemical relapse and later as metastatic disease over time. The aim of mCSPC treatment is to prolong survival, improve quality of life and reduce complications. The properties of some agents used in mCSPC are summarized in Table 1.

\section{Androgen Deprivation Therapy in MCSPC}

PC is a hormone-dependent disease like breast cancer. Androgens are hormones that play a key role in the growth of cancer cells (5). Testosterone and dihydrotestosterone (DHT) are the two main androgens in men. Of testosterone $90-95 \%$ is synthesized from testis Leydig cells and $5-10 \%$ from the adrenal glands (6). Circulating testosterone is converted into the active form DHT in the cell by the $5-\alpha$ reductase enzyme, and DHT acts on the androgen receptor (7).

Huggins and Hodges (8) showed that PC was an androgen sensitive disease and that the disease could regress by lowering the testosterone level by performing bilateral orchiectomy. Androgen deprivation therapy (ADT) is the standard treatment in $\mathrm{mCSPC}$. ADT can be performed with surgical castration (bilateral orchiectomy) or it can be performed medically. In medical castration; gonadotropin releasing hormone (GnRH) agonists (e.g., leuprolide, goserelin, buserelin, triptorelin...) or GnRH antagonists (degarelix) can be used. Testosterone synthesis is suppressed through the hypothalamus-pituitarygonad axis with medical castration (9). Although the majority of patients respond to ADT, resistance to castration develops in most of the patients within 1-3 years (10). 


\begin{tabular}{|c|c|c|c|c|}
\hline & Docetaxel & Abiraterone acetate & Enzalutamide & Apalutamide \\
\hline Route of administration & intravenous & oral & oral & oral \\
\hline Dosage & 75 mg/m² & $1000 \mathrm{mg} / \mathrm{d}$ & $160 \mathrm{mg} / \mathrm{d}$ & $240 \mathrm{mg} / \mathrm{d}$ \\
\hline Need for prednisone & $\sqrt{ }$ & $\sqrt{ }$ & & \\
\hline Decrease in seizure threshold & & & $\sqrt{ }$ & \\
\hline Liver toxicity & & $\sqrt{ }$ & Lesser & \\
\hline Risk of hypertension & & $\sqrt{ }$ & $\sqrt{ }$ & $\sqrt{ }$ \\
\hline Febrile neutropenia & $\sqrt{ }$ & & & \\
\hline Neuropathy & $\sqrt{ }$ & & & \\
\hline Rash & & & & $\sqrt{ }$ \\
\hline Treatment duration & 6 cures & Until progression & Until progression & Until progression \\
\hline
\end{tabular}

Antiandrogens used in PC treatment are divided into two as steroidal and non-steroidal ones. Steroidal anti-androgens are synthetic derivatives of hydroxyprogesterone. In addition to blocking androgen receptors in the periphery, these agents have testosterone-lowering and progestational properties with pituitary inhibition. In addition to inhibiting gonadotropin release, they also suppress adrenal activity. They are not recommended for use as monotherapy. They are associated with lower overall survival (OS) rate than luteinizing hormonereleasing hormone (LHRH) analogues (11). Non-steroidal antiandrogens (e.g., bicalutamide, nilutamide, flutamide) are agents with better quality of life and compliance as they do not lower testosterone levels. Bone mineral density, physical performance and libido are protected with these agents. In a meta-analysis including 2717 patients with advanced stage PC, it was shown that non-steroidal antiandrogens were associated with lower OS rate compared to LHRH agonists (12). In a randomized study comparing steroidal and nonsteroidal antiandrogens, survival data of flutamide and cyproterone acetate were found to be similar (13).

\section{Chemotherapy in mCSPC}

The addition of cytotoxic chemotherapy (CT) to the standard treatment in mCSPC has resulted in improvements in survival and quality of life $(14,15)$. In studies investigating the role of CT in $\mathrm{MCSPC}$, it has been tried to find an answer to the question of whether there is a survival benefit.

In the CHAARTED study by Sweeney et al. (16), 790 patients with $\mathrm{mCSPC}$ were randomized one-on-one to either the ADT arm or ADT + docetaxel ( $75 \mathrm{mg} / \mathrm{m}^{2}$ every 21 days, 6 cycles) arm. The primary endpoint of the study was OS. In the CHAARTED study, the presence of 4 or more bony lesions, at least one of which was extra-vertebrae or extrapelvic, or extranodal visceral metastasis was defined as a high-volume disease. The median OS was 57.6 vs 49.2 months when all patients were evaluated [95\% confidence interval $(\mathrm{Cl})=0.47-0.80 ; \mathrm{p}<0.001]$. Median OS in patients with high volume disease was 49.2 and 32.2 months [hazard ratio $(\mathrm{HR})=0.61,95 \% \mathrm{Cl}=0.45-0.81 ; \mathrm{p}<0.001$ ] and there was no statistically significant difference between treatment arms in terms of median OS in patients with low-volume disease $(p=0.11)$. Among grade $3-4$ side effects; neutropenia was detected in $12.1 \%$, febrile neutropenia in $6.1 \%$ and fatigue in $4.1 \%$ of the patients in the combination arm. As a result, adding docetaxel to ADT provided a statistically significant benefit in OS in high-volume disease (16).

In the open-label, randomized, phase 3 GETUG-AFU 15 study, 385 patients with a diagnosis of $\mathrm{mCSPC}$ were randomized oneon-one to either the ADT arm or ADT + docetaxel $(75 \mathrm{mg} /$ $\mathrm{m}^{2}$ every 21 days, 9 cycles) arm. The primary endpoint of the study was OS, and the secondary endpoint was biochemical and radiological progression-free survival (PFS). The median follow-up period was 50 months. The median OS was 58.9 vs 54.2 months $(95 \% \mathrm{Cl}=0.75-1.36)$ in the treatment groups. Three-year OS was $64.2 \%$ in the ADT arm and $62.9 \%$ in the combination arm. The most common grade 3-4 side effects in the combination arm were neutropenia, febrile neutropenia, and fatigue. Consequently, the OS benefit of adding docetaxel to standard therapy could not be demonstrated in this study (17).

In arm C of the multi-arm STAMPEDE trial, patients were randomized one-on-one to either standard therapy or standard therapy + docetaxel ( 6 cycles of $75 \mathrm{mg} / \mathrm{m}^{2}$ every 21 days). The primary endpoint of the study was OS. The median follow-up period was 43 months. The median OS was 71 months in the standard treatment arm and 81 months in the combination $\operatorname{arm}(\mathrm{HR}=0.78 ; 95 \% \mathrm{Cl}=0.66-0.93 ; \mathrm{p}=0.006)$. Of the patients, $77 \%$ were able to complete 6 cycles of docetaxel treatment in the combination arm. Grade 3-5 side effects were observed in $32 \%$ of the standard treatment arm and $52 \%$ of the standard treatment + docetaxel arm. The most common grade 3-5 side effects in the combination arm were neutropenia and febrile neutropenia. Similar to the CHAARTED study, in this study, the survival benefit of adding docetaxel to ADT was shown (18).

A meta-analysis of 5 studies investigating the benefit of adding docetaxel CT to standard treatment in patients with PC was published in Lancet Oncology in 2016. In this meta-analysis, the OS benefit of adding docetaxel to standard therapy was demonstrated ( $\mathrm{HR}=0.77,95 \% \mathrm{Cl}=0.68-0.87 ; \mathrm{p}<0.0001)$. Absolute improvement in four-year survival was $9 \%(95 \% \mathrm{Cl}=5$ 14). Addition of docetaxel to standard treatment also provided a statistically significant benefit in disease-free survival (DFS) $(\mathrm{HR}=0.64 ; \mathrm{p}<0.0001)$. Absolute improvement in four-year DFS 
was $16 \%$ (95\% Cl=12-19) (19). Phase 3 ADT + CT studies in mCSPC are shown in Table 2.

\section{mCSPC and Abirateron Acetate}

Abiraterone acetate (AA) is an inhibitor of the cytochrome P-450c17 (CYP17) enzyme, which is a critical enzyme in extragonadal and testicular androgen synthesis. It inhibits both $17 \alpha$-hydroxylase and C17-20-lyase by dual function. Testosterone precursors inhibit the formation of dehydroepiandrosterone and androstenedione (20). Various studies have been carried out to demonstrate the survival benefit, efficacy, and side effects of AA in $\mathrm{mCSPC}(21,22)$.

In the double-blind, phase 3, placebo-controlled LATTITUDE study, 1199 patients were randomized one-on-one to either the ADT + AA + prednisolone arm or ADT + placebo arm. The primary endpoint of the study was OS and radiological PFS. Patients with MCSPC who were aged 18 years or older, had an ECOG performance score of $0-2$, and had 2 of 3 high risk factors (Gleason's score $\geq 8, \geq 3$ bone metastasis, visceral metastasis) were included in the study. While OS endpoint could not be reached in the combination arm, it was 34.7 months $(H R=0.62$; 95\% Cl=0.51-0.76; $\mathrm{p}<0.001)$ in the ADT arm. Radiological PFS was 33 months in the combination arm and 14.7 months in the ADT arm ( $\mathrm{HR}=0.47 ; 95 \% \mathrm{Cl}=0.39-0.55 ; \mathrm{p}<0.001)$. All secondary endpoints were statistically significant in favor of the combination arm. Grade 3 or above side effects including hypertension, hypokalemia, increase in alanine aminotransferase and aspartate aminotransferase, and hyperglycemia were more in the AA arm. With this study, the addition of AA + prednisolone to the standard treatment ADT statistically prolonged OS and radiological PFS in patients with a diagnosis of $\mathrm{MCSPC}$ (21).

In the multi-arm STAMPEDE study, 1917 patients were randomized individually to either the ADT or ADT + AA + prednisolone arm. The primary endpoint of the study was OS. The median age at diagnosis was 67, the median PSA level was $53 \mathrm{ng} / \mathrm{mL}$, and $52 \%$ of the patients were metastatic. The median follow-up period was 40 months. The three-year OS was $76 \%$ vs $83 \%$ and was in favor of the combination arm (HR=0.63; $95 \%$ $\mathrm{Cl}=0.52-0.76 ; \mathrm{p}<0.001)$. Three-year event-free survival was $75 \%$ vs $45 \%$ in favor of the $A A$ arm $(H R=0.29 ; 95 \% \mathrm{Cl}=0.25-$ $0.34 ; \mathrm{p}<0.001)$. Grade $3-5$ side effects were observed in $47 \%$ of the combination arm and $33 \%$ of the monotherapy arm. Hypertension, cardiovascular and hepatic disorders were more common in the combination arm. Symptomatic skeletal related events were less common in the combination arm $(\mathrm{HR}=0.46$; 95\% $\mathrm{Cl}=0.37-0.58 ; \mathrm{p}<0.001)(22)$.

There are no studies directly comparing AA with docetaxel, but in a meta-analysis of seven studies, AA + ADT provided a 19\% reduction in the risk of death compared to docetaxel + ADT $(\mathrm{HR}=0.81 ; 95 \% \mathrm{Cl}=0.66-1.00)$ (23). In the multi-armed, multicenter STAMPEDE study, 189 (14\%) of 1348 patients received docetaxel + ADT and $377(28 \%)$ received AA + ADT. In the indirect comparison of docetaxel + ADT and AA + ADT in the STAMPEDE study; median age was 66, median PSA was $56 \mathrm{ng} /$ $\mathrm{mL}$. HR was 1.16 (95\% Cl 0.82-1.65) for OS; HR was $0.51(95 \%$ $\mathrm{Cl} 0.39-0.67)$ for event free survival; and HR was $0.65(95 \%$ $\mathrm{Cl}=0.48-0.88)$ for PFS (24).

\section{mCSPC and Enzalutamide}

Enzalutamide, a new generation androgen receptor blocker, blocks the DHT receptor both on the target cell surface and on the nucleus, thanks to its high receptor affinity. It is an orally used agent that has been shown to be effective in patients who have developed resistance to first generation non-steroidal antiandrogens such as bicalutamide, nilutamide, and flutamide (25).

In the double-blind, phase 3 ARCHES study in which the benefit of enzalutamide on survival was investigated, 1150 patients with a diagnosis of $\mathrm{MCSPC}$ were randomized either to the enzalutamide + ADT arm or placebo + ADT arm. The primary endpoint of the study was radiological PFS. The risk of radiological progression and death was statistically significantly lower in the enzalutamide + ADT arm (HR=0.39; 95\% Cl=0.30$0.50 ; \mathrm{p}<0.001)$. Enzalutamide + ADT therapy reduced the risk of PSA progression, initiation of new antineoplastic therapy, skeletal related events, and CSPC and pain progression. The frequency of grade 3 or above side effects was $24.3 \%$ in the enzalutamide + ADT arm and $25.6 \%$ in the placebo + ADT arm (26).

In another open-label, phase 3, randomized ENZAMET study in which the survival benefit of enzalutamide was investigated, 1125 patients with mCSPC were randomized either to the ADT + standard non-steroidal antiandrogen (bicalutamide, nilutamide, flutamide) arm or ADT + enzalutamide arm. The primary endpoint of the study was OS. The median follow-up duration was 34 months. There were 102 deaths in the enzalutamide arm and 143 deaths in the standard non-steroidal antiandrogen arm (HR=0.67; 95\% Cl=0.52-0.86; $\mathrm{p}=0.002)$. Three-year OS rate was $80 \%$ vs $72 \%$, which was in favor of the enzalutamide arm. Three-year PFS rate was $67 \%$ vs $37 \%$, which was in favor of the enzalutamide $\operatorname{arm}(\mathrm{HR}=0.39 ; 95 \% \mathrm{Cl}=0.33-0.47 ; \mathrm{p}<0.001)$. Treatment discontinuation due to side effects was more in the enzalutamide arm. Seizures were seen in $7(1 \%)$ patients in the enzalutamide arm. In that study, the addition of enzalutamide provided a statistically significant advantage in terms of OS and PFS in patients with a diagnosis of $\mathrm{MCSPC}(27)$.

\begin{tabular}{|c|c|c|c|c|c|}
\hline Trial name & $\begin{array}{l}\text { Number of } \\
\text { patients }\end{array}$ & $\mathrm{CT}$ regimen & $\begin{array}{l}\text { Primary end } \\
\text { point }\end{array}$ & OS duration & $\mathrm{HR}(95 \% \mathrm{Cl})$ \\
\hline CHAARTED & 790 & Docetaxel $75 \mathrm{mg} / \mathrm{m}^{2}, 6$ cures & OS & Median 57.6 vs 44 months & $0.61(0.47-0.80)$ \\
\hline GETUG-AFU 15 & 385 & Docetaxel $75 \mathrm{mg} / \mathrm{m}^{2}, 9$ cures & OS & Median 58.9 vs 54.2 months & $1.01(0.75-1.36)$ \\
\hline STAMPEDE- C arm & 1776 & Docetaxel $75 \mathrm{mg} / \mathrm{m}^{2}, 6$ cures & OS & Median 81 vs 71 months & $0.78(0.66-0.93)$ \\
\hline
\end{tabular}

ADT: Androgen deprivation therapy, CT: Chemotherapy, mCSPC: Metastatic castration sensitive prostate cancer, OS: Overall survival, HR: Hazard ratio, Cl: Confidence interval 
In a study comparing enzalutamide with $\mathrm{AA}+$ prednisone indirectly, in the predosetaxel and postdosetaxel periods, better results were obtained with enzalutamide in terms of radiological PFS, PSA response rate and time until PSA progression; while there was no difference between the two agents in terms of OS (28).

\section{mCSPC and Apalutamide}

Apalutamide is a non-steroidal antiandrogen agent used in the treatment of PC. Apalutamide binds directly to the ligand binding portion of the androgen receptor and prevents androgen receptor translocation, DNA binding, and androgen receptor-mediated transcription (29).

In the phase 3, randomized, double-blind, placebo-controlled TITAN trial, 1052 patients with mCSPK were randomized oneon-one either to ADT + apalutamide arm or ADT + placebo arm. Apalutamid was given orally with a dose of $240 \mathrm{mg} /$ day. The primary endpoints were radiologic PFS and OS. Demographic and clinical characteristics of the patients were well balanced. The median age in both groups was 68. Of the patients, $10.7 \%$ previously received docetaxel treatment; $62.7 \%$ had high-volume disease, and $37.3 \%$ had low-volume disease. One of the primary endpoints, the radiologic PFS at 24 months, was $68.2 \%$ in the apalutamide arm and $47.5 \%$ in the placebo arm $(\mathrm{HR}=0.48 ; 95 \% \mathrm{Cl}=0.39-0.60 ; \mathrm{p}<0.001)$. The first interim analysis for OS was performed after 200 deaths were observed ( 83 in the apalutamide group and 117 in the placebo group). Another primary endpoint, OS at 24 months, was $82.4 \%$ in the apalutamide arm versus $73.5 \%$ in the placebo $\operatorname{arm}(\mathrm{HR}=0.67 ; 95 \% \mathrm{Cl}=0.51-0.89 ; \mathrm{p}=0.005)$. The risk of death in the apalutamide arm was lower by $33 \%$. The frequency of grade 3-4 side effects was $42.2 \%$ in the apalutamide arm compared to $40.8 \%$ in the placebo group, and rash was more common in the apalutamide arm. Forty two patients (8.0\%) in the apalutamide arm and 28 patients (5.3\%) in the placebo arm could not continue treatment because of adverse effects. As a result, adding apalutamide to ADT significantly prolonged OS and radiologic PFS in patients with a diagnosis of $\mathrm{MCSPC}$, and no significant difference was found between the two arms in terms of side effect profile (30). Phase 3 studies of hormonal treatment agents used in $\mathrm{MCSPC}$ are shown in Table 3.

\section{Should Zolendronic Acid be Used in the mCSPC?}

Bisphosphonates, which are synthetic pyrophosphate analogues, accumulate in bone binding to hydroxyapatite crystals and suppress the function of osteoclasts (31). Zolendronic acid, a powerful third generation bisphosphonate, has been shown to reduce the incidence of skeletal related events in patients with a diagnosis of $\mathrm{mCSPC}$ (32).

In the multi-arm STAMPEDE study, the contribution of adding zolendronic acid to standard therapy was investigated. Patients were randomized either to the standard therapy arm or standard therapy + zolendronic acid arm. The median OS was 71 months in the standard treatment arm and was not achieved in the standard therapy + zolendronic acid arm (HR=0.94, 95\% $\mathrm{Cl}=0.79-1.11 ; \mathrm{p}=0.450)$. There was also no statistical difference in terms of event-free survivals. In this study, the skeletal related event, OS and event-free survival benefits of adding zolendronic acid to standard therapy could not be demonstrated. In a metaanalysis published in Lancet Oncology, the benefit of skeletal related events and OS [95\% Cl=0.94 (0.83-1.07); $\mathrm{p}=0.323$ ] of zolendronic acid in mCSPC could not be demonstrated (19).

\section{The Role of Local Treatment in Metastatic Disease}

Radical prostatectomy (RP) or radiotherapy (RT) are the standard treatment options in PC with a life expectancy of $\geq 10$ years and organ limited PC (33). ADT + RT is widely used in locally advanced disease. The effect of local treatment to the prostate on survival in patients with metastatic PC has been searched for a long time.

In the multi-center HORRAD study; 432 patients with PC with primary bone metastasis and PSA $>20 \mathrm{ng} / \mathrm{mL}$ were randomized one-on-one to either the standard ADT arm or ADT + RT arm. In the RT arm, a total of 70 Gy RT was given in 35 fractions within 3 months after ADT. Primary endpoint was OS. The secondary endpoint was time to PSA progression. The median OS was 45 months in the ADT + RT arm and 43 months in the ADT arm $(H R=0.90 ; 95 \% \mathrm{Cl}=0.70-1.14 ; \mathrm{p}=0.4)$, and there was no statistically significant difference. The time to median PSA progression was 15 months in the RT arm and 12 months in the ADT arm (HR=0.78; 95\% $\mathrm{Cl}=0.63-0.97 ; \mathrm{p}=0.02)$, and a statistically significant difference was found (34).

In the phase 3 STAMPEDE study in which 2061 patients with newly diagnosed metastatic PC were included, patients were randomized individually to either the ADT arm or ADT + RT arm. Primary endpoint was OS. Of the patients, $40 \%$ had lowvolume disease and $54 \%$ had high-volume disease. Three-year OS was $62 \%$ in the ADT arm and $65 \%$ in the RT arm (HR=0.92;

\begin{tabular}{|c|c|c|c|c|c|c|}
\hline Trial ame & $\begin{array}{l}\text { Number of } \\
\text { patients }\end{array}$ & Agent used & $\begin{array}{l}\text { Primary end } \\
\text { point }\end{array}$ & $\begin{array}{l}\text { Duration for } \\
\text { radiological PFS }\end{array}$ & OS duration & $\begin{array}{l}\text { HR of OS } \\
(95 \% \mathrm{CI})\end{array}$ \\
\hline LATTITUDE & 1199 & abiraterone acetate & $\begin{array}{l}\text { OS } \\
\text { Radiological PFS }\end{array}$ & 33 vs 14.8 months & $\begin{array}{l}\text { While the median value could not be } \\
\text { reached in the AA arm, the median value } \\
\text { was } 34.7 \text { months in the control arm. }\end{array}$ & $\begin{array}{l}0.62 \\
(0.51-0.76)\end{array}$ \\
\hline STAMPEDE & 1917 & abiraterone acetate & OS & & $\begin{array}{l}\text { OS at } 36^{\text {th }} \text { month } \\
\% 83 \text { vs } \% 76\end{array}$ & $\begin{array}{l}0.63 \\
(0.52-0.76)\end{array}$ \\
\hline ENZAMET & 1125 & enzalutamide & OS & & $\begin{array}{l}\text { OS at } 36^{\text {th }} \text { month } \\
80 \% \text { vs } 72 \%\end{array}$ & $\begin{array}{l}0.67 \\
(0.52-0.86)\end{array}$ \\
\hline TITAN & 1052 & apalutamide & $\begin{array}{l}\text { OS } \\
\text { Radiological PFS }\end{array}$ & $\begin{array}{l}\text { At } 24^{\text {th }} \text { month } \\
68.2 \% \text { vs } 47.5 \%\end{array}$ & $\begin{array}{l}\text { OS at } 24^{\text {th }} \text { month } \\
68.2 \% \text { vs } 47.5 \%\end{array}$ & $\begin{array}{l}0.67 \\
(0.51-0.89)\end{array}$ \\
\hline
\end{tabular}


95\% $\mathrm{Cl}=0.80-1.06 ; \mathrm{p}=0.266)$. The 3-year event-free survival was $23 \%$ in the ADT arm and $32 \%$ in the RT arm (HR=0.76; $95 \% \mathrm{Cl}=0.68-0.84 ; \mathrm{p}<0.0001)$. When subgroup analyzes were evaluated, it was shown that adding RT to ADT in low-volume disease significantly prolonged OS (HR $=0.68 ; 95 \% \mathrm{Cl}=0.52$ $0.90 ; p=0.0098)(35)$. Phase 3 prostate RT studies in metastatic $\mathrm{PC}$ are shown in Table 4.

\begin{tabular}{|l|l|l|l|l|}
\hline \multicolumn{5}{|c|}{ Table 4. Phase 3 prostate RT trials in metastatic PC } \\
\hline Trial name & $\begin{array}{l}\text { Number of } \\
\text { patients }\end{array}$ & $\begin{array}{l}\text { Primary } \\
\text { end point }\end{array}$ & $\begin{array}{l}\text { OS } \\
\text { duration }\end{array}$ & HR $(95 \% \mathrm{Cl})$ \\
\hline HORRAD & 432 & OS & $\begin{array}{l}45 \text { vs } 43 \\
\text { months }\end{array}$ & $0.90(0.70-1.14)$ \\
\hline STAMPEDE & 2061 & OS & $\begin{array}{l}65 \% \text { vs } \\
62 \% \text { for } 36 \\
\text { months }\end{array}$ & $0.76(0.68-0.84)$ \\
\hline
\end{tabular}

PC: Prostate cancer, OS: Overall survival, HR: Hazard ratio, Cl: Confidence interval, RT: Radiotherapy

In a meta-analysis evaluating the results of 3 studies investigating the effect of RT to the prostate on survival in patients with mCSPC, there was no statistically significant difference in terms of OS $(\mathrm{HR}=0.92 ; 95 \% \mathrm{Cl}=0.81-1.04, \mathrm{p}=0.195)$ and $\mathrm{PFS}(\mathrm{HR}=0.94 ; 95 \%$ $\mathrm{Cl}=0.84-1.05, \mathrm{p}=0.238)$, while there was improvement in terms of biochemical progression $(\mathrm{HR}=0.74 ; 95 \% \mathrm{Cl}=0.67-0.82)$ and in event-free survival ( $\mathrm{HR}=0.76,95 \% \mathrm{Cl}=0.69-0.84)$ in $\mathrm{RT}$ arm (36). The role of local treatment for primary tumor in patients with metatastic PC was investigated in a reprospective study by Culp et al. (37). In the study, data of 8185 patients were scanned. Of those, 7811 patients did not receive local treatment, 245 patients received RP and 129 patients received brachytherapy. Five-year OS was $67.4 \%$ in the RP arm and $52.6 \%$ in the non-treated arm $(p<0.001)$. In another retrospective study conducted by Gratzke et al. (38), while 1464 of 1538 patients with metastatic PC did not receive local treatment, 245 patients received RP. Five-year OS was $55 \%$ in the RP arm and $21 \%$ in the non-locally treated $\operatorname{arm}(\mathrm{p}<0.01)$.

\section{Cost}

Various therapeutic agents can be used in the treatment of mCSPC and there is a financial toxicity brought by these agents. The cost of docetaxel CT for 6 cures is approximately 6000 Turkish Liras (TL), but the treatment of conditions such as febrile neutropenia that may arise due to CT-related toxicities may increase this cost. Monthly costs of new generation antiandrogen treatments range between 6,000 and 10,000 TL.

\section{Conclusion}

The treatment of PC has been changing rapidly in recent years. Many therapeutic agents are started to be used in the early period of the disease, and the survival results of our patients are happily improving. Since the introduction of docetaxel in 2004, many agents in the groups of CT, new hormonal therapies, immunotherapy and radionuclides have been approved in various stages of PC and have entered clinical use. However, there are no head-to-head randomized controlled trials with these agents. For this reason, many features such as patient characteristics, efficacy, accessibility to treatment, experience, toxicity, drug-drug interactions, expected side effects and cost should be evaluated together in treatment selection.

\section{Acknowledgements}

Publication: The results of the study were not published in full or in part in form of abstracts.

Contribution: There is not any contributors who may not be listed as authors.

Conflict of Interest: No conflict of interest was declared by the authors.

Financial Disclosure: The authors declared that this study received no financial support.

\section{Ethics}

Peer-review: Externally peer-reviewed.

\section{Authorship Contributions}

Concept: M.G., Y.Ü., Design: M.G., Y.Ü., Data Collection and Processing: M.G., Y.Ü., Analysis and Interpretation: M.G., Y.Ü., Literature Search: M.G., Y.Ü., Writing: M.G., Y.Ü.

\section{References}

1. Bray F, Ferlay J, Soerjomataram I, et al. Global cancer statistics 2018: GLOBOCAN estimates of incidence and mortality worlwide for 36 centers in 185 countries. CA Cancer J Clin 2018;68:394-424.

2. Siegel RL, Miller KD, Jemal A. Cancer statistics, 2019. CA Cancer J Clin 2019;69:7-34.

3. Culp MB, Soerjomataram I, Efstathiou JA, et al. Recent Global Patterns in Prostate Cancer Incidence and Mortality Rates. Eur Urol 2020;77:38-52.

4. Türkyılmaz M, Hacıkamiloğlu E, Baran Deniz E, et al. Türkiye kanser istatistikleri 2015. Türkiye Cumhuriyeti Sağlık Bakanlığı, Halk Sağlığı Genel Müdürlüğü, Ankara, 2018. Available: https://hsgm. saglik.gov.tr/depo/birimler/kanser-db/istatistik/Trkiye_Kanser_ statistikleri_2015.pdf

5. Machtens S, Schultheiss D, Kuczyk M, et al. The history of endocrine therapy of benign and malignant diseases of the prostate. World J Urol 2000;18:222-226.

6. Labrie F. Adrenal androgens and intracrinology. Semin Reprod Med 2004;22:299-309.

7. Azzouni F, Godoy A, Li Y, Mohler J. The 5 alpha-reductase isozyme family: a review of basic biology and their role in human diseases. Adv Urol 2012;2012:530121.

8. Huggins C, Hodges CV. Studies on prostatic cancer: I. The effect of castration, of estrogen and of androgen injection on serum phosphatases in metastatic carcinoma of the prostate. CA Cancer J Clin 1972;22:232-240.

9. Assikis V], Simons JW. Novel therapeutic strategies for androgenindependent prostate cancer: an update. Semin Oncol 2004;31:26-32.

10. Sweeney C, Chen Y, Carducci M, et al. Chemohormonal therapy versus hormonal therapy for hormone naive newly metastatic prostate cancer: ECOG-led randomized trial. Ann Oncol 2014;25(Suppl 4):iv256.

11. Moffat LE. Comparison of Zoladex, diethylstilbestrol and cyproterone acetate treatment in advanced prostate cancer. Eur Urol 1990;18 Suppl 3:26-27. 
12. Seidenfeld J, Samson DJ, Hasselblad V, et al. Single-therapy androgen suppression in men with advanced prostate cancer: a systematic review and meta-analysis. Ann Intern Med 2000;132:566-577.

13. Schröder FH, Whelan P, De Reijke TM, et al. Members of the EORTC Genito-Urinary Group. Metastatic prostate cancer treated by flutamide versus cyproterone acetate. Final analysis of the "European Organization for Research and Treatment of Cancer" (EORTC) Protocol 30892. Eur Urol 2004;45:457-464.

14. Petrylak DP, Tangen CM, Hussain MH, et al. Docetaxel and estramustine compared with mitoxantrone and prednisone for advanced refractory prostate cancer. N Engl J Med 2004;351:1513-1520.

15. Tannock IF, De Wit R, Berry WR, et al. Docetaxel plus prednisone or mitoxantrone plus prednisone for advanced prostate cancer. $\mathrm{N}$ Engl J Med 2004;351:1502-1512.

16. Sweeney C], Chen YH, Carducci M, et al. Chemohormonal Therapy in Metastatic Hormone-Sensitive Prostate Cancer. N Engl J Med 2015;373:737-746.

17. Gravis G, Fizazi K, Joly F, et al. Androgen-deprivation therapy alone or with docetaxel in non-castrate metastatic prostate cancer (GETUGAFU 15): a randomised, open-label, phase 3 trial. Lancet Oncol 2013;14:149-158.

18. James ND, Sydes MR, Clarke NW, et al. Addition of docetaxel, zoledronic acid, or both to first-line long-term hormone therapy in prostate cancer (STAMPEDE): survival results from an adaptive, multiarm, multistage, platform randomised controlled trial. Lancet 2016;387:1163-1177.

19. Vale $\mathrm{CL}$, Burdett $\mathrm{S}$, Rydzewska $\mathrm{LH}$, et al. Addition of docetaxel or bisphosphonates to standard of care in men with localised or metastatic, hormone-sensitive prostate cancer: a systematic review and metaanalyses of aggregate data. Lancet Oncol 2016;17:243-256.

20. Yap TA, Carden P, Attard G, de Bono JS. Targeting CYP17: established and novel approaches in prostate cancer. Curr Opin Pharmacol 2008;8:449-457.

21. Fizazi K, Tran NP, Fein L, et al. Abiraterone plus prednisone in metastatic, castration-sensitive prostate cancer. $N$ Engl J Med 2017;377:352-360.

22. James ND, de Bono JS, Spears MR, et al. Abiraterone for prostate cancer not previously treated with hormone therapy. N Engl J Med 2017;377:338-351.

23. San Tan P, Aguiar P, Haaland B, Lopes G. Addition of abiraterone, docetaxel, bisphosphonate, celecoxib or combinations to androgendeprivation therapy (ADT) for metastatic hormone-sensitive prostate cancer (mHSPC): a network meta-analysis. Prostate Cancer Prostatic Dis 2018;21:516-523.

24. Sydes MR, Spears MR, Mason MD, et al. Adding abiraterone or docetaxel to long-term hormone therapy for prostate cancer: directly randomised data from the STAMPEDE multi-arm, multi-stage platform protocol. Ann Oncol 2018;29:1235-1248.

25. Tran C, Ouk S, Clegg NJ, et al. Development of a second-generation antiandrogen for treatment of advanced prostate cancer. Science 2009;324:787-790.

26. Amstrong AJ, Szmulewitz RZ, Petrylak DP, et al. ARCHES: A randomized, phase III study of androgen deprivation therapy with enzalutamide or placebo in men with metastatic hormone-sensitive prostate cancer. J Clin Oncol 2019;37:2974-2986.

27. Davis ID, Martin AJ, Stockler MR, et al. Enzalutamide with Standard First-Line Therapy in Metastatic Prostate Cancer. N Engl J Med 2019;381:121-131.

28. Chopra A, Georgieva M, Lopes G, et al. Abiraterone or Enzalutamide in Advanced Castration Resistant Prostate Cancer: An Indirect Comparison. Prostate 2017;77:639-646.

29. Al-Salama ZT. Apalutamide: First global approval. Drugs 2018;78:699-705.

30. Chi KN, Agarwal N, Bjartell A, et al. Apalutamide for Metastatic, Castration-Sensitive Prostate Cancer. N Engl J Med 2019;381:13-24.

31. Diamond $\mathrm{TH}$, Bucci J, Kersley $\mathrm{JH}$, et al. Osteoporosis and spinal fractures in men with prostate cancer: risk factors and effects of androgen deprivation therapy. J Urol 2004;172:529-532.

32. Saad F, Gleason DM, Murray R, et al. A randomized, placebo-controlled trial of zoledronic acid in patients with hormone-refractory metastatic prostate carcinoma. J Natl Cancer Inst 2002;94:1458-1468.

33. Scardino P. Update: NCCN prostate cancer clinical practice guidelines. J Natl Compr Canc Netw 2005;3 Suppl 1:S29-S33.

34. Boevé LMS, Hulshof MCCM, Vis AN, et al. Effect on survival of androgen deprivation therapy alone compared to androgen deprivation therapy combined with concurrent radiation therapy to the prostate in patients with primary bone metastatic prostate cancer in a prospective randomised clinical trial: data from the HORRAD trial. Eur Urol 2019;75:410-418.

35. Parker CC, James ND, Brawley CD, et al. Radiotherapy to the primary tumour for newly diagnosed, metastatic prostate cancer (STAMPEDE): a randomised controlled phase 3 trial. Lancet 2018;392:2353-2366.

36. Burdett $S$, Boeve LM, Ingleby FC, et al. Prostate radiotherapy for metastatic hormone-sensitive prostate cancer: a STOPCAP systematic review and meta-analysis. Eur Urol 2019;76:115-124.

37. Culp SH, Schellhammer PF, Williams MB. Might men diagnosed with metastatic prostate cancer benefit from definitive treatment of the primary tumor? A SEER-based study. Eur Urol 2014;65:1058-1066.

38. Gratzke C, Engel J, Stief CG. Role of radical prostatectomy in metastatic prostate cancer: data from the Munich Cancer Registry. Eur Urol 2014;66:602-603. 